\title{
Docentes no ensino superior: apontamentos acerca da formação profissional
}

\author{
Teachers in higher education: notes about professional training
}

\section{Profesores de educación superior: apuntes sobre la formación profesional}

\author{
Andressa Abreu da Silva ${ }^{1}$ \\ Manuela Ciconetto Bernardi ${ }^{2}$
}

\section{Resumo}

$\mathrm{O}$ artigo visa a discutir a formação profissional dos docentes que atuam no Ensino Superior. O estudo promove apontamentos embasados em dados anuais do Censo da Educação realizado pelo Instituto Nacional de Estudos e Pesquisa Educacionais Anísio Teixeira (INEP) e dos autores Almeida e Pimenta (2014), Charlot (2012), Freire (1996), Nóvoa (2017) e Veiga (2006). Constata-se lacunas na formação profissional dos docentes para a atuação no Ensino Superior, principalmente, concernentes às práticas do cotidiano escolar, percebe-se a preparação dos professores com uma ênfase para a investigação científica e não à docência. A necessidade de mudanças envolve, em especial, a legislação vigente, a formação inicial, continuada e aperfeiçoamentos. Apesar de compreendermos a complexidade desses processos, problematizamos e sugerimos meios para que a formação não resulte em lacunas, além de instigarmos o aprimoramento na formação inicial, a atualização e especialização pela formação continuada com vistas a um processo que propicie a atuação do profissional no Ensino Superior de forma plena.

Palavras-chave: Formação Docente; Formação profissional; Ensino Superior.

\begin{abstract}
The article aims to discuss the professional training of teacher working in Higher Education. The study promotes notes based on annual data from the Education Census conducted by the National Institute of Educational Studies and Research Anísio Teixeira (INEP) and the authors Almeida and Pimenta (2014), Charlot (2012), Freire (1996), Nóvoa (2017) and Veiga (2006). There are gaps in the professional training of teachers to work in Higher Education, especially concerning the practices of everyday school, it is clear that they are prepared in the emphasis on scientific research and not teaching. The need for changes involves, in particular, the current legislation, initial, continuing training and improvements. Although we understand the complexity of these processes, we problematize and suggest ways so that the training does not result in gaps, in addition to instigating the improvement in the initial training, the updating and specialization for the continuous training with a view to a process that allows the performance of the professional in teaching Higher Education.
\end{abstract}

Keywords: Teacher Training; Professional training; Higher Education.

\footnotetext{
${ }^{1}$ Licenciada em Matemática. Mestre em Educação pela Universidade de Caxias do Sul (2020). E-mail: andressaabreusilva0@gmail.com; ORCID: https://orcid.org/0000-0002-7036-5975

${ }^{2}$ Bacharel em Biblioteconomia. Mestre em Educação pela Universidade de Caxias do Sul (2020). E-mail mcbernardi1@ucs.br; ORCID: https://orcid.org/0000-0002-0130-4845
} 


\section{Resumen}

El artículo tiene como objetivo discutir la formación profesional de los profesores que trabajan en la Educación Superior. El estudio promueve apuntes basados en datos anuales del Censo Educativo realizado por el Instituto Nacional de Estudios e Investigaciones Educativas Anísio Teixeira (INEP) y los autores Almeida y Pimenta (2014), Charlot (2012), Freire (1996), Nóvoa (2017). ) y Veiga (2006). Existen vacíos en la formación profesional de los docentes para desempeñarse en la Educación Superior, principalmente en lo referente a las prácticas escolares diarias, es claro que se están preparando con énfasis en la investigación científica y no en la docencia. La necesidad de cambios implica, en particular, la legislación vigente, la formación inicial, continua y las mejoras. Si bien entendemos la complejidad de estos procesos, problematizamos y sugerimos caminos para que la formación no resulte en brechas, además de instigar la mejora en la formación inicial, la actualización y especialización para la formación continua con miras a un proceso que Permite el desempeño del profesional en Docencia Totalmente superior.

Palabras clave: Formación del profesorado; Formación profesional; Educación superior.

\section{Introdução}

A formação profissional dos docentes que atuam no Ensino Superior é a temática sobre a qual mobilizamos as discussões do presente estudo. O Ensino Superior viu a sua expansão nas últimas décadas, tanto de forma pública quanto particular, por meio da criação de novas instituições e de um aumento considerável de profissionais. Nesse sentido, o perfil profissional também tem sido ressignificado.

Na contramão desse fluxo, a formação do docente que irá atuar nesse nível de ensino não é determinada por legislação e relegada às instruções, não obrigatórias, que indicam percursos formativos como Programas de Pós-Graduação em nível de mestrados e doutorados. Muitas vezes, a formação direciona-se à constituição de pesquisadores, colocando de lado conhecimentos mobilizados no ambiente escolar, em especial, aos que se voltarão ao exercício profissional do Ensino Superior (ARAÚJO, 2005). Como consequência, ficam lacunas na formação que serão percebidas na prática quando o profissional assumir a docência no Ensino Superior.

O principal objetivo deste estudo é corroborar com a temática de formação de docentes para o Ensino Superior, incitando mudanças e aperfeiçoamentos ao problematizar a formação atual, realizada predominantemente por mestrados e doutorados. Atualmente, assim como os autores que embasam a investigação, percebe-se que as formações apresentam lacunas para a docência no Ensino Superior. 
Propomos que os caminhos a serem percorridos para a resolução envolverão mudanças na legislação vigente, na formação inicial, cursos de formação continuada e aperfeiçoamentos. Para tal, o estudo é uma pesquisa teórica de cunho qualitativo, assim, discussões de pressupostos teóricos e dados do Inep referentes aos censos da educação superior de 2008, 2018 e 2019 são mobilizados.

\section{Método}

A pesquisa científica é definida por Gerhardt e Silveira (2009) como a atividade da ciência, pois possibilita uma aproximação e entendimento da realidade a investigar. Os autores consideram a pesquisa como um processo permanentemente inacabado que se desenvolve por meio de aproximações sucessivas da realidade, fornecendo-nos subsídios para possibilitar uma intervenção no real. A pesquisa científica pode ser empírica ou teórica e, ainda, analisar os dados construídos de forma qualitativa, quantitativa ou quantitativaqualitativa.

O objetivo da análise qualitativa é analisar o objeto de pesquisa em relação ao seu meio natural, sem focar em representações numéricas, mas sim "com aspectos da realidade que não podem ser quantificados, centrando-se na compreensão e explicação da dinâmica das relações sociais" (GERHARDT; SILVEIRA, 2009, p. 32). Por este motivo, ela carrega subjetividade, ademais, quando referem-se às Ciências Humanas, muitas pesquisas apresentam esta característica por serem intangíveis e analisarem comportamentos humanos. As pesquisas teóricas buscam nas publicações, informações e conhecimentos já produzidos sobre um determinado tema, com vistas a responder o problema base (FONSECA, 2002), o que também se constitui como essencial à pesquisa científica, haja vista, o embasamento e relações entre os pares para a construção do conhecimento.

Dessa forma, o delineamento metodológico neste estudo é situado como uma análise qualitativa de cunho teórico, pois apresenta estudos já realizados e dados de censos. Seu propósito é a produção de reflexões acerca da formação docente para o Ensino Superior, visando a compreender tanto a situação atual de formação, como a possível trajetória deste profissional e/ou lacunas que advém dessa formação. 
Os textos foram selecionados de uma gama ofertada na disciplina sobre docência no Ensino Superior ${ }^{3}$ e também por pesquisa na base de dados Google Acadêmico, utilizando como palavras-chave "docência no Ensino Superior", "formação docente para o Ensino Superior" e "formação docente em mestrados e doutorados". Como principais autores, destacamos Almeida e Pimenta (2014), Charlot (2012), Freire (1996), Nóvoa (2017) e Veiga (2006), entendendo que suas contribuições são reconhecidamente ${ }^{4}$ relevantes para a temática da qual aqui tratamos.

\section{Docentes Do Ensino Superior: Notas Do Perfil Profissional}

Para analisarmos a formação profissional dos docentes que atuam no Ensino Superior, é necessário entender a sua situação atual na educação brasileira. Diversas mudanças no perfil do profissional vêm ocorrendo, aliadas à expansão das universidades públicas nas últimas décadas e abertura de cursos de licenciaturas e bacharelados em instituições privadas, políticas que incrementaram e apoiaram um maior espaço para o Ensino Superior (SOARES, CUNHA, 2010), tem-se atualmente um número elevado de profissionais que trabalham na área.

Precisamente, o censo ${ }^{5}$ de 2018 expôs a atuação de 384.474 docentes no Ensino Superior (INEP, 2018) já o de 2019, apresentou um total de 386.073 docentes vinculados às redes pública e privada do país (INEP, 2019), em apenas um ano isso corresponde a um incremento de aproximadamente $0,5 \%$. Esse número fica mais expressivo se compararmos a quantidade de docentes que atuavam em 2008, que era constituída por 321.493 docentes, representando aproximadamente 17\% a menos do que é apresentado em 2019 (INEP, 2018). $\mathrm{O}$ que nos coloca frente a um espaço cada vez maior ao Ensino Superior e às vagas para profissionais da educação atuarem.

Se pensarmos no ensino público e na formação dos docentes do Ensino Superior, o censo de 2008 indicou que 27,5\% deles tinham como formação a especialização (INEP,

\footnotetext{
${ }^{3}$ Disciplina "Docência no Ensino Superior", ministrada pela professora Dra. Andreia Mores, entre Agosto a Dezembro de 2020 do curso de Pós-Graduação em Educação (Mestrado Acadêmico) da Universidade de Caxias do Sul.

${ }^{4}$ Por serem frequentemente citados e utilizados para embasar as principais pesquisas da área.

${ }^{5}$ Os censos divulgados pelo Instituto Nacional de Estudos e Pesquisas Educacionais Anísio Teixeira (INEP), são fontes de informações relevantes para a compreensão da Educação Superior no país, pois possibilitam o monitoramento e oportunizam a verificação de problemas no ensino.
} 
2018). Dez anos depois, esse percentual reduziu para 10,2\% (INEP, 2018), indicando uma queda de 17,3\% e esse número continuou caindo, apenas um ano depois, 9,3\% dos docentes possuíam especialização como formação (INEP, 2019).

Percebe-se que o corpo docente pendia à especialização e foi diminuindo ao longo do tempo, sendo substituído pela formação inicial mais uma titulação, o que corrobora com o Parecer 977/65 (BRASIL, 1965) que consolida a pós-graduação como uma formação para professores do Ensino Superior. Em 2008, o percentual de professores com doutorado na rede pública era de 44,3\% (INEP, 2018), nos censos mais recentes, as porcentagens compõem 64,3\% das instituições em 2018 (INEP, 2018) e 66\% para o ano de 2019 (INEP, 2019), todavia o percentual que possuía ao menos uma titulação, como mestrado, é uma característica mais antiga que se apresenta (GIOLO, 2006).

Ao buscar por diferenças entre licenciaturas e bacharelados, percebemos que em 2018 licenciaturas eram constituídas por 58,2\% de professores doutores, 31,15\% de professores mestres e menos de $10 \%$ de especialistas, já para bacharelados, a porcentagem de doutores é um pouco menor, sendo 52,4\% de doutores, 35,6\% de professores mestres e $12 \%$ de especialistas para os cursos presenciais (INEP, 2018).

Comparando esses dados com os publicados no censo de 2019, há um aumento no número de docentes com doutorado, já que em 2019, 59,9\% dos docentes da licenciatura e $55,1 \%$ dos docentes do bacharelado possuíam doutorado. Isso corresponde a um aumento de $1,7 \%$ de professores com doutorado para as licenciaturas e de 2,7\% para os bacharelados (INEP, 2019). Referenciando o próprio censo de 2019 “a participação de docentes com doutorado, tanto na rede pública quanto na rede privada continua crescendo. A participação dos que têm até especialização cai a cada ano nas duas redes." (INEP, 2019, p. 26).

Outro dado relevante é o tipo de regime de trabalho dos docentes do Ensino Superior, que pode ser integral, parcial ou horista. Este revela a condição de trabalho à qual os docentes estão submetidos. Nas instituições públicas, a participação de docentes em tempo integral era de 76,1\%, subindo para 86,3\% em 2018 e mantendo o índice de 86,3\% em 2019, mostrando um aumento significativo nos últimos 10 anos. Nas redes privadas, houve diminuição de docentes no regime de horista, sendo 57,7\% em 2008, caindo para 30,1\% em 2018 e após um ano equivalia a 29,9\% (INEP, 2018, 2019). 
Quanto à formação requerida, diferentemente dos docentes do Ensino Fundamental e Médio, para os quais há exigência ${ }^{6}$ de curso superior por meio das licenciaturas, não há normativa específica para a formação do docente no Ensino Superior (ARAÚJO, 2005), o que existem são direcionamentos e a situação atual, que pende à titulação, remete à Lei $\mathrm{n}^{\circ}$ 9.394/96 de Diretrizes e Bases que no Art. 52 define que as universidades devem possuir, no mínimo, um terço do corpo docente titulados por stricto sensu para comporem o quadro das instituições de Ensino Superiores.

O Art. 66 dispõe que aos profissionais da educação "a preparação para o exercício do magistério superior far-se-á em nível de pós-graduação, prioritariamente em programas de mestrado e doutorado" (BRASIL, 1996), dispositivo que desde 2004 deve ser assumido pelas instituições, todavia “embora a expressão 'far-se-á' possua uma conotação imperativa, essa preparação não tem tido a força legal própria de um dispositivo de formação e nem se configura como condição para ingresso ou permanência da docência no Ensino Superior" (SOARES, CUNHA, 2010, p. 582).

Com quase 400.000 docentes atuantes no Ensino Superior, cabe uma análise sobre a temática $^{7}$, já que é necessário compreender os saberes adquiridos e a formação desses profissionais, pois ela se reflete nos resultados do Ensino Superior, mas também é desdobrada na inserção, no cotidiano e no processo de ensino-aprendizagem dos alunos. Nesse sentido, nos deslocamos a seguir para explorar os saberes necessários à docência do Ensino Superior.

\section{A Docência no Ensino Superior e os saberes para o exercício da profissão}

Para contextualizarmos as atividades ao exercício da profissão, cabe pensar no que é a docência, "no sentido etimológico, docência tem suas raízes no latim, docere, que significa ensinar, instruir, mostrar, indicar, dar a entender. [...] No sentido formal, docência é o trabalho dos professores." (VEIGA, 2006, p. 85), atuação que implica tanto na complexidade do

\footnotetext{
${ }^{6} \mathrm{~A}$ exigência é requerida, porém temos ciência de um número de professores que não chegaram a obter a graduação em fases anteriores e por isso são liberados para atuação. Essa questão também é pertinente no Ensino Superior e embasada pelo notório saber, especialidade técnica ou estabilidade no emprego (GIOLO, 2006).

${ }^{7}$ Compreendemos que não é um assunto inédito, foi e é discutido por inúmeros autores nas últimas décadas (NÓVOA, 2017; SOARES, CUNHA, 2010) e ganha relevância na atualidade, conforme apontam Almeida e Pimenta (2014), todavia justificamos essa pesquisa em virtude da pertinência e de dados recentes, como os fornecidos pelas pesquisas do Inep. Dessa forma, buscamos auxiliar na discussão da temática e vincular informações sobre a atual situação brasileira no que concerne à formação de docentes.
} 
processo desenvolvido dentro da sala de aula, como o transcende pelas tarefas queo professor desenvolve.

Sob outra perspectiva, a função do trabalho docente de acordo com Charlot (2012, p. 13) "não é ensinar, mas sim fazer com que os alunos aprendam", as instituições de ensino seriam locais para o aprendizado discente, sendo o professor um meio que propicia condições para o aprendizado. Pedagogia que se aproximará muito do que Paulo Freire assumia ao explicar que o ensino não é transmissão de conhecimento (FREIRE, 1996).

De toda forma, profissionais vinculados à docência de universidades terão especificidades para a atuação, imbricados por uma complexidade que irá se explicar " porque seu exercício, além de envolver condições singulares, exige uma multiplicidade de saberes [...] competências e atitudes que precisam ser apropriados e compreendidos em suas relações" (SOARES; CUNHA, 2010, p. 586).

Até porque o aprendizado do docente será determinante "do que se ensina, para que se ensina e dos modos como se ensina e que são próprias da atividade educativa de ensinar" (ALMEIDA; PIMENTA, 2014, p. 12). O que coloca em evidência a importância da formação para o exercício da profissão (VEIGA, 2006; ALMEIDA; PIMENTA, 2014), ao pensarmos nela mais precisamente na finalidade, Almeida e Pimenta (2014, p. 8) explicam que a universidade $^{8}$

É uma instituição educativa cuja finalidade é o permanente exercício da crítica, que se sustenta na pesquisa, no ensino e na extensão, ou seja, a produção do conhecimento a partir da problematização dos conhecimentos historicamente produzidos e de seus resultados na construção da sociedade humana e dos novos desafios e demandas que esta coloca.

O espaço propício ao aprendizado deve promover o desenvolvimento do conhecimento, da criticidade, sendo a instituição de Ensino Superior um local complexo, independente de ser público ou privado (ARAÚJO, 2005). Nesse espaço, os professores desenvolverão diversas atividades que irão além de ministrar aulas (VEIGA, 2006). Pesquisa,

\footnotetext{
${ }^{8}$ Utilizamos de forma abrangente o termo instituições de Ensino Superior conforme nosso objeto de estudo, todavia procuramos na discussão incluir especificidades das universidades por considerarmos que elas se distinguem das faculdades ao serem um conjunto de instituições que irão priorizar a tríade "ensino, pesquisa e extensão", ademais, ao pensarmos na formação de professores e a atual configuração que prioriza o stricto sensu, isso nos leva diretamente a olhar para universidades.
} 
orientação, bancas, supervisões além das atividades constantes na Lei no 9.394/96 como a participação na elaboração do projeto pedagógico, plano de ensino e planejamento. Ademais, muitos dos docentes estão vinculados ao regime de dedicação exclusiva, elemento que deve ser considerado a se pensar nas funções exercidas.

Atividades que denotam "um perfil que se caracteriza pela diversidade, pela pluralidade de opções, caminhos, interesses e tensões" (ARAÚJO, 2005, p. 41) A diversidade e a pluralidade de perfis docentes, que podemos encontrar no Ensino Superior, podem ter origem nas diversidades de formatos de instituições como universidades, faculdades, institutos (públicos ou privados) e, principalmente, na gama de cursos que são ofertados pelas instituições, com distintas áreas do conhecimento. Veiga (2006, p. 87) destaca que

A docência universitária exige a indissociabilidade entre ensino, pesquisa e extensão. Faz parte dessa característica integradora a produção do conhecimento bem como sua socialização. A indissociabilidade aponta para a atividade reflexiva e problematizadora do futuro profissional.

A tríade explicada pela autora é o suporte para o desenvolvimento das atividades docentes e aponta para a formação profissional dos que irão atuar, ou seja, está atrelada aos saberes produzidos no percurso formativo. Visto isso, justifica-se a importância de compreender a formação. Conforme já exposto, não há exigência para atuar no Ensino Superior e, sim, direcionamentos. Frisamos que nos "chama a atenção nas políticas públicas a não exigência de uma formação para o professor da educação superior que contemple os saberes específicos da docência" (SOARES, CUNHA, 2010, p. 580) e

Como se sabe, a pós-graduação stricto sensu (programas de mestrado e doutorado) em áreas distintas da educacional está voltada para a formação de pesquisadores em seus campos específicos de conhecimento e não à formação de professores, o que significa que para estes profissionais não lhes são dadas as condições institucionais para se formar na docência. (ARAÚJO, 2005, p. 42)

É também o que se percebe ao analisar a estrutura curricular dos Programas de PósGraduação, com ênfase na formação de pesquisadores e não no desenvolvimento de habilidades e competências. Essa ênfase parece ter sido assumida pelos Programas como se os saberes investigativos se transformassem em saberes docentes (SOARES, CUNHA, 2010). 
Almeida e Pimenta (2014) destacam que os cursos de mestrado e doutorado tendem a preparar para o exercício da pesquisa científica, contudo, isso não garante que o mestre ou doutor esteja apto para exercer a docência,“o professor universitário não tem uma formação voltada para os processos de ensino e aprendizagem pelos quais é responsável quando inicia sua vida acadêmica" (ALMEIDA; PIMENTA, 2014, p. 12).

Essa visão tradicional de formação, conforme explica Araújo (2005), que prioriza o domínio de um campo do conhecimento, advém de uma concepção positivista/mecanicista calcada pelo paradigma dominante, da qual, desconsidera outros meios de compreensão do conhecimento, como as relações do contexto e as subjetividades. Almeida e Pimenta (2014) também expõem essa problemática

Os elementos constitutivos de sua atuação docente, como relação da disciplina com o projeto do curso, planejamento, organização da aula, metodologias e estratégias didáticas, avaliação, peculiaridades da interação professor-aluno, lhe são desconhecidos, bem como a compreensão do sentido e do significado de sua área específica na formação dos estudantes como sujeitos e cidadãos, questões essas determinantes do que se ensina, do para que se ensina e dos modos como se ensina e que são próprias da atividade educativa de ensinar. (ALMEIDA; PIMENTA, 2014, p. 12).

Embora tenha elevado o nível de formação - conforme vimos pelos censos (INEP, 2018, 2019) - o futuro docente não adquire nos estudos formativos ênfase nos processos aos quais precisa para atuar na docência, ademais, Araújo (2005) alerta que esse fato acontece, principalmente, em programas de Pós-Graduação não vinculados à área educacional.

De fato, os programas voltados à Educação estariam atrelados às questões escolares e no seu plano de ensino incluiriam saberes necessários ao ambiente escolar, todavia, isso não corresponde à totalidade e a grande parte de programas de outros campos específicos do conhecimento, mas que se enquadram na formação stricto sensu e dos quais, consequentemente, geram profissionais que acabam atuando no Ensino Superior. Ademais a concepção da formação docente resultante da atividade investigativa, "parece estar vinculada ao princípio da indissociabilidade entre ensino e pesquisa" (SOARES, CUNHA, 2010, p. 582).

Um outro problema que elencamos é abordado por Almeida e Pimenta (2014), ao criticarem o modelo de ingresso para a docência do Ensino Superior. A prova didática constitui parte relevante da seleção e não examina a competência didática, focando em um 
domínio de conhecimento (ALMEIDA; PIMENTA, 2014), corroborando a formação tradicional que temos hoje em dia, conforme já apontado por Araújo (2005).

Nóvoa (2017) atenta para um problema a ser considerado das licenciaturas, que muitas vezes, se apresentam como "bacharelados disfarçados", contendo alta carga horária de formação específica e pouca carga horária voltada para a formação docente. Se compreendermos que a licenciatura já é um meio do aluno chegar à Pós-Graduação com lacunas à formação para atuação futura na docência do Ensino Superior, considerando que eles possuem carga horária voltada para práticas, tem-se conforme Nóvoa (2017), problemas já no que tange aos bacharelados.

Após ingressarem, percebemos lacunas evidenciadas em dificuldades ao assumir a função como docente, verificadas em estudos como os que Araújo (2005) realizou, ao investigar saberes de docentes iniciantes do Ensino Superior e cabe uma análise das suas considerações

\footnotetext{
No decorrer da pesquisa, as dificuldades apontadas pelos professores iniciantes na construção dos saberes necessários à docência universitária demonstraram haver por parte desses um certo desconhecimento acerca da complexidade da docência, bem como um certo despreparo das questões referentes aos processsos de ensinar e aprender. Os resultados demonstraram que os professores se ressentem diante do déficit de formação pedagógica para lidar com as questões específicas da atividade de ensino e aprendizagem. Isso indica necessidades formativas, ou um maior investimento na formação contínua dos professores universitários. (ARAÚJO, 2005, p. 203)
}

Araújo (2005, p. 203) propõe "necessidades formativas" ou optar pela formação continuada. Pesquisas como as da autora, evidenciam um problema e assim como este trabalho, o colocam em evidência já que "o primeiro passo da mudança é reconhecer a existência de um problema" (NÓVOA, 2017, p. 1111) e discutir alternativas e soluções. É o que faremos a seguir.

\section{A Formação para o Exercício da Docência no Ensino Superior}

O Ensino Superior não tem caráter obrigatório e não há regulamentação em forma de Lei para a formação do docente que atuará nesse nível de ensino, excetuando-se o Art. 66 da 
LDB (BRASIL, 1996) que indica a formação dos docentes que atuarão no Ensino Superior para a pós-graduação. Na seção anterior, percebemos lacunas e frisamos que a origem do problema estaria na formação dos docentes.

Veiga (2006, p. 92) nos expõe que o professor "precisa ter necessariamente competência pedagógica e científica" e que é possível que o Ensino Superior se transforme em uma educação baseada em vocação técnico científica e vocação humanística. Dessa forma, o caminho, ao nosso ver, não seria diminuir a relevância da pesquisa "mas, sim, reforçar a necessidade de estabelecer caminhos que permitam o diálogo em outros campos do conhecimento" (ARAÚJO, 2005, p. 43).

Sem a pretensão de diminuir a importância dos saberes adquiridos pela formação atual, mas pensando a exemplo no déficit que Almeida e Pimenta (2014), propomos ${ }^{9}$ de certa maneira, como primeiro passo, uma equidade na aquisição de conhecimentos para que o profissional possa atuar a nível de pesquisa, quanto o capacite ao ambiente escolar.

Uma formação da qual sejam estabelecidas bases que possam preencher ao menos algumas ${ }^{10}$ lacunas hoje encontradas nas formações, essa seria uma primeira etapa do processo e um grande avanço já que ainda "são raras as instituições que assumem claramente a importância dos saberes pedagógicos" (SOARES, CUNHA, 2010, p. 582) o reconhecimento e a legitimidade das instituições propiciaria os primeiros avanços.

No caso de mestrados e doutorados, seria possível inserir atividades que corroborem para a sua formação a fim de preparar à prática da docência e não apenas à pesquisa, elementos que não carecem de um tempo maior, mas de uma redistribuição do plano de ensino, o que seria possível tendo em vista a flexibilidade dada pelo Parecer 977/65 do Conselho Federal de Educação "em função das peculiaridades de cada setor de conhecimento [...]” (BRASIL, 1965, p. 170).

\footnotetext{
${ }^{9}$ Situamo-nos no que Nóvoa (2017) caracteriza como transformadores no campo de debate da educação, reconhecemos a necessidade da mudança na formação de professores e não vemos como alternativas as lógicas de mercado e desintegração de instituições, assim como o autor expõe, "apesar das suas fragilidades, [universidades] têm um papel insubstituível na afirmação dos professores e da educação pública" (NÓVOA, 2017, p. 1111)

${ }^{10}$ Entendemos que mesmo com a equidade não é possível formar um profissional docente de forma integral e acabada para assumir a função. A concepção de Freire (1996) que o professor é um ser inacabado, que se constituirá ao longo do trajeto é algo inerente ao docente e por isso também adquirirá conhecimentos e precisará atualizar-se frente às demandas (com formações e especializações). Dessa forma, a proposta na equidade se baseia em constituir uma base para o início das suas funções, entendendo que ela não é a solução ou o fim da formação.
} 
Além dos saberes, entendemos como fundamentais na constituição do docente do Ensino Superior as relações externas e a prática para inseri-lo na futura profissão. O contato não só por estágios, mas para edificar uma formação apoiada na realidade e com profissionais de diferentes áreas, assim "é necessário construir um novo arranjo institucional, dentro das universidades, mas com fortes ligações externas, para cuidar da formação de professores" (NÓVOA, 2017, p. 1114), desinstitucionalizar as universidades e promover uma nova forma de aprendizado por meio de um novo modelo de escola/formação seria importante.

Não queremos gerar uma relação dicotômica entre teoria e prática, mas enfatizar que elas se complementam e andam concomitantes para uma formação de qualidade. A teoria é importante, pois se o docente não tiver domínio na área do conhecimento em que atuará, não terá possibilidades de criar práticas que auxiliem no conhecimento do aluno. Já a prática, se constitui como fundamental para a docência, diferenciando um docente de um técnico.

Nóvoa (2017) exemplifica a diferença comparando, por exemplo, o conhecimento que um professor de Matemática possui e o que um especialista precisa. $\mathrm{O}$ autor afirma que ambos são diferentes, o matemático estuda para demonstrar teoremas, não necessitando repassar saberes, enquanto um licenciado trabalhará com a questão humana, tendo alunos de diversos níveis, aplicando linguagem e conhecimentos diferentes com vista à produção do saber discente.

Outro elemento é que se torna imperioso rever a concepção da representação do docente que atua pelo dom de ensinar. Veiga (2006) defende que a docência é, formalmente, entendida como o trabalho dos professores, sendo de fato uma profissão. A representação do docente nato (PIMENTA; ANASTASIOU, 2012) que há muito foi construída, implica e desqualifica na preparação do profissional.

Nessa perspectiva, seria assentada somente a formação no treinamento prático. Nóvoa (2017, p. 1111) explica que "a formação docente deve ter como matriz a formação para uma profissão”. Assim, vê-se a necessidade de valorizar essa etapa inicial, ademais, questões práticas remetem ao que Araújo (2005) pontua e já destacamos aqui, ou seja, uma formação tradicional, que leva em conta somente uma área.

Dessa forma, vê-se ainda que as formações obrigatórias oferecidas pelas instituições também não são suficientes - a pensar na continuidade de aprendizado dos docentes (FREIRE, 1996) - para o exercício da profissão, o que exige a busca por formações e especializações que respaldam o ensino. Entendemos essa como outra etapa na formação de professores, não 
menos importante como a formação base, mas como de fato, uma etapa importante que apoie e subsidie a continuidade dos conhecimentos.

Existe um rol de pesquisas realizadas que indicam que a construção da identidade do professor universitário decorre "das vivências familiares, dos modelos de antigos professores, da própria experiência autodidata, das trocas com colegas e do feedback dos estudantes." (SOARES; CUNHA, 2010, p. 580) Elementos esses que são transversais e ocorrem ao longo da vida. Em virtude disso, as mesmas autoras afirmam que "esses estudos convergem no sentido do reconhecimento da necessidade de programas institucionais de formação continuada" 11 .

Concomitante, o ensino requer formação para a atualização dos conteúdos ou aprofundamento. Entende-se que "o ensino é uma atividade que requer conhecimentos específicos, consolidados por meio de formação voltada especialmente para esse fim, bem como atualização constante das abordagens dos conteúdos e das novas maneiras de ensinálos" (ALMEIDA; PIMENTA, 2014, p. 13).

A formação continuada, levando-se em conta o contexto atual de formação docente, pode ser utilizada para cobrir a defasagem ocorrida na formação inicial e/ou atualizar conhecimentos antes não adquiridos. Pensando nos apontamentos que propomos, tendo em vista a atuação da docência no Ensino Superior, a formação continuada se torna um meio ${ }^{12}$ para que se possa sanar os problemas já expostos.

Nesse sentido, Veiga (2006) afirma que as instituições podem oferecer cursos de formação continuada, para que seja possível criar uma correlação entre formação acadêmica elevada e competência pedagógica. Mas, entende-se que esses cursos seriam necessários e importantes já a formação inicial, a "base" para o preparo, não relegando aos cursos externos ou formações continuadas à formação que os docentes precisam adquirir.

Todavia, existem alguns problemas relacionados aos cursos de formação continuada. Muitas vezes, as instituições oferecem cursos para os docentes, cuja participação tende a ser obrigatória. A obrigatoriedade da participação nem sempre significa resultados positivos ou

\footnotetext{
${ }^{11}$ Refletimos além da docência, que o conhecimento humano está em movimento e em construção, não sendo fixo e na docência necessitará de meios para a apropriação. Conhecimento que temos ciência da necessidade de atualização e continuidade (FREIRE, 1996).

${ }^{12}$ Entendemos que a formação continuada deve ser utilizada como um meio no momento atual mas não como uma solução definitiva. Ela cobre as feridas expostas, mas a base, como já referido, está na formação inicial, deslocando a formação continuada para de fato conforme o próprio nome se refere, uma continuidade dos conhecimentos.
} 
qualidade formativa (ALMEIDA; PIMENTA, 2014), mesmo quando obrigados a participar, muitos professores não apresentam abertura para as formações, o que pode não incitar mudanças na prática e/ou aquisição de conhecimentos.

São questões que devem ser problematizadas e frisadas para a compreensão do contexto de formação de professores, pois vemos e reconhecemos que há um problema nesse percurso e que são necessárias mudanças, conforme problematizado por Nóvoa (2017).

Em termos de políticas institucionais, Almeida e Pimenta (2014) acreditam que, se incrementadas para a formação continuada de docentes, elas poderiam unificar as tentativas isoladas de docentes para ter formação pedagógica, como os seminários, cursos e, até mesmo, estágios. É uma das possibilidades que vê-se emergir da atual situação. Assim, as instituições poderiam

propor alguns indicadores para a organização de uma política de formação docente institucional: compromisso das instituições universitárias para criar as condições que tornem possível esse processo; determinação em caminhar rumo a uma cultura de colaboração; concepção de formação ligada à prática docente e que compreenda a inovação e a formação como elementos complementares da organização da política formativa; apostar em ações que tenham relação com a qualidade da docência, potencializando e gerando interesses pela melhora do ensino; gerar os elementos condicionantes capazes de integrar em uma mesma política as atuações sobre avaliação, desenvolvimento profissional e inovação. Com isso, argumentamos em favor de uma real valorização do empenho na formulação de políticas institucionais de formação, estáveis e permanentes, voltadas para o aprimoramento da atividade de ensinar, compreendida como um dos componentes essenciais para assegurar a qualidade do trabalho na universidade contemporânea. (ALMEIDA; PIMENTA, 2014, p. 16).

Dessa forma, os docentes teriam a oportunidade de se aprimorar profissionalmente, melhorando seu conhecimento e desempenho didático, e conforme pontuado anteriormente é uma das possibilidades existentes perante a atual situação na formação de docentes do Ensino Superior, mas também se levanta a reflexão sobre estas políticas como formas de preenchimento de lacunas para uma formação principal inicial. Essa questão é abordada por Almeida e Pimenta (2014). Compreendemos que, talvez como uma fase inicial de uma mudança necessária para a formação docente, e que poderia ser seguida de modificações nos cursos de Pós-Graduação, seria manter a formação continuada como uma formação complementar e que se apoiasse a formação a longo prazo, mas que não se situasse mais 
como a base da formação desse profissional. Ideamos um futuro, com as questões já sanadas, em que a formação continuada seria utilizada para a continuidade dos saberes e propiciar conhecimentos em determinadas e específicas áreas.

Veiga (2006) apresenta baseada no Fórum Nacional de pró-reitores de Graduação das Universidades Brasileiras (2004), o Forgrad, um novo perfil docente do Ensino Superior para o futuro, que requer uma formação científica específica na área de conhecimento de atuação; nível de formação mínimo como a pós-graduação, priorizando o doutorado; conhecimento sobre o processo histórico de constituição de sua área de atuação e sobre os métodos que a constituíram; competência pedagógica. Seriam esses quesitos um conjunto de elementos que apoiariam uma visão global na formação docente. Assim, esses elementos partiriam de uma base concreta e sólida para o início da formação, com um estudo aprofundado pela titulação e que o profissional tendo uma formação continuada e estendida, se aprofundaria em certos conhecimentos para, dessa forma, constituir-se o percurso formativo como docente.

Nóvoa (2017, p. 1113) ressalta que é necessária a construção de modelos de formação que "valorizem a preparação, a entrada e o desenvolvimento profissional docente". O autor destaca três dimensões para a formação, sendo elas: o desenvolvimento de uma vida cultural e científica; a ética e a preparação para agir num ambiente de incerteza e imprevisibilidade. Sem dúvidas, é necessária a contribuição como os de Nóvoa (2017), que tragam discussões de como devem ser as formações, e que nesse caso, enfatizam caminhos possíveis para a formação.

A primeira dimensão apontada pelo autor compreende os docentes como pessoas que devem ter contato regular com a leitura, cultura e ciência para que possam inspirar os estudantes para tal. A segunda dimensão compreende a existência de um comprometimento moral e ético. A terceira e última dimensão diz respeito à consciência do docente estar preparado para a imprevisibilidade, para perguntas inesperadas que possam surgir, por exemplo. Nóvoa (2017) reforça que a formação é fundamental não somente para preparar o docente de forma técnica ou pedagógica, mas para construir o profissional docente. As três dimensões são indicativas para a formação seja feita de modo global para a sua constituição, contemplando questões culturais, éticas e atitudinais.

\section{Considerações Finais}


O presente trabalho objetivou uma discussão acerca da formação dos docentes que atuam no Ensino Superior. No percurso, foi analisada a situação da formação pelos censos do Inep referentes à 2008, 2018 e 2019 (INEP, 2018, 2019). Vimos também especificidades relativas ao regime de trabalho e à inexistência de uma exigência formativa para atuar nesse nível de ensino. Seguimos na compreensão do que é a docência e qual a função dos docentes nessas instituições, a complexidade que o trabalho exige e por isso os saberes bases para essa atuação.

Percebemos, por diversos autores, que as formações stricto sensu que são indicadas para o processo formativo, oferecem em sua maioria, uma formação tradicional, com prioridade para as atividades de pesquisa e não para atuação em sala de aula e no ensino. Por conseguinte, vimos algumas das possibilidades para que as lacunas formativas sejam amenizadas, bem como ideamos um futuro pensando na formação dos docentes. A legislação vigente necessita de mudanças para que o ciclo desde a graduação, Pós-Graduação e formações sejam modificados, a fim de preparar profissionais para a atuação docente e não só para a pesquisa.

Entre sugestões, merecem destaque as trajetórias propostas que versam sobre a formação continuada como foco nas práticas para que seu posterior deslocamento se efetive como principal componente dos currículos de Pós-Graduação, organizando os currículos e os tempos escolares entre teoria e prática.

Por fim, as reflexões produzidas versam corroborar a discussão sobre a formação docente para o Ensino Superior, compreendendo que esta é uma questão necessária e permanente, já que a área é dinâmica e necessita que os interessados estejam em constante diálogo em busca de aprimoramento.

\section{Referências}

ALMEIDA, Maria Isabel de; PIMENTA, Selma Garrido. Pedagogia universitária: Valorizando o ensino e a docência na universidade. Rev. Port. de Educação, Braga, v. 27, n. 2, p. 7-31, jun. 2014. Disponível em:

http://www.scielo.mec.pt/scielo.php?script=sci_arttext\&pid=S087191872014000200002\&lng=pt\&nrm=iso. Acesso em 31 mar. 2020.

ARAÚJO, Kátia Costa Lima Corrêa de. Os saberes docentes dos professores iniciantes do Ensino Superior: um estudo na Universidade Federal de Pernambuco. 2005. Dissertação (Mestrado em Educação) - Universidade Federal de Pernambuco, Recife, 2005. Disponível em: https://repositorio.ufpe.br/bitstream/123456789/4702/1/arquivo5809_1.pdf. Acesso em 06 jan. 2021. 
BRASIL. CONSELHO FEDERAL DE EDUCAÇÃO . Parecer CFE n. 977/65. Revista Brasileira de Educação, n. 30, 2005.

BRASIL. Instituto Nacional de Estudos e Pesquisas Educacionais Anísio Teixeira (Inep). Censo da Educação Superior 2018: notas estatísticas. Brasília, 2019. Disponível em: http://download.inep.gov.br/educacao_superior/censo_superior/documentos/2019/censo_da_e ducacao_superior_2018-notas_estatisticas.pdf._Acesso em 07 maio 2020.

BRASIL. Instituto Nacional de Estudos e Pesquisas Educacionais Anísio Teixeira (Inep). Notas Estatísticas 2019: censo da Educação Superior. Disponível em: https://download.inep.gov.br/educacao_superior/censo_superior/documentos/2020/Notas_Est atisticas_Censo_da_Educacao_Superior_2019.pdf Acesso em 12 jan. 2020.

BRASIL. Lei no 9.394, de 20 de dezembro de 1996. Estabelece as diretrizes e bases da educação nacional. Disponível em: http://www.planalto.gov.br/ccivil_03/leis/19394.htm. Acesso em 05 jan. 2021.

CHARLOT, Bernad. A mobilização no exercício da profissão docente. Revista Contemporânea de Educação, v. 7, n. 13, p. 10-26, jul. 2012. Disponível em: https://revistas.ufrj.br/index.php/rce/article/view/1655/1504. Acesso em 06 maio 2020.

FREIRE, Paulo. Pedagogia da autonomia: saberes necessários à prática educativa. São Paulo: Paz e Terra, 1996.

FONSECA, João José Saraiva. Metodologia da pesquisa científica. Fortaleza: UEC, 2002.

GERHARDT, Tatiana Engel; SILVEIRA, Denise Tolfo. Métodos de Pesquisa. Porto Alegre: Universidade Federal do Rio Grande do Sul, 2009. Disponível em: http://www.ufrgs.br/cursopgdr/downloadsSerie/derad005.pdf. Acesso em 15 maio 2020.

GIOLO, Jaime. Os docentes da educação superior brasileira. In: RISTOFF, Dilvo; SEVEGNANI, Palmira. Docência na educação superior. Brasília: Instituto Nacional de Estudos e Pesquisas Educacionais Anísio Teixeira, 2006. (Coleção Educação Superior em Debate. Vol. 5). p. 19-46. Disponível em: http://portal.inep.gov.br/documents/186968/489018/Doc\%C3\%AAncia+na+Educa\%C3\%A7 \%C3\%A3o+Superior/997400de-a6c1-4aa7-a06c-b586dc4d6412?version=1.1. Acesso em 15 jan. 2021.

NOVOA, António. Firmar a posição como professor, afirmar a profissão docente. Cad. Pesqui., São Paulo, v. 47, n. 166, p. 1106-1133, Dec. 2017. Disponível em: http://www.scielo.br/scielo.php?script=sci_arttext\&pid=S0100$15742017000401106 \& \operatorname{lng}=$ en \&nrm=iso. Acesso em 22 abr. 2020.

PIMENTA, Selma Garrido; ANASTASIOU, Léa das Graças Camargos. Docência no Ensino Superior. São Paulo, SP: Cortez Editora, 2002.

SOARES, Sandra Rregina; CUNHA, Maria Isabel da. Programa de Pós-Graduação em Educação: lugar de Formação da Docência Universitária? Revista Brasileira de PósGraduação. Brasília, v. 7, n. 14, p. 577-604, 2010. Disponível em: http://ojs.rbpg.capes.gov.br/index.php/rbpg/article/view/18/14. Acesso em 25 jan. 2021. 
VEIGA, Ilma Passos Alencastro. Docência Universitária na Educação Superior. In: RISTOFF, Dilvo; SEVEGNANI, Palmira. Docência na educação superior. Brasília: Instituto Nacional de Estudos e Pesquisas Educacionais Anísio Teixeira, 2006. (Coleção Educação Superior em Debate. Vol. 5). p. 85-95. Disponível em:

http://portal.inep.gov.br/documents/186968/489018/Doc\%C3\%AAncia+na+Educa\%C3\%A7 $\% \mathrm{C} 3 \% \mathrm{~A} 3 \mathrm{o}+$ Superior/997400de-a6c1-4aa7-a06c-b586dc4d6412?version=1.1. Acesso em 15 jan. 2021.

Recebido em: junho/2021. Aprovado em: setembro/2021. 